\title{
ONREL
}

NREL is a national laboratory of the U. S. Department of Energy, Office of Energy Efficiency and Renewable Energy, operated by the Alliance for Sustainable Energy, LLC.

\section{Transportation Secure Data Center (TSDC)}

OVERVIEW: SECURE ARCHIVAL OF AND ACCESS TO REAL-WORLD DATA

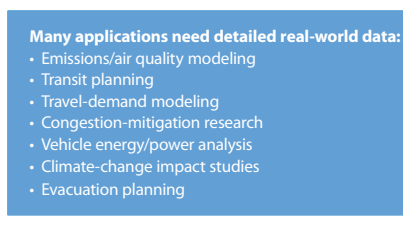

Recent increases in global
positioning system (GPS) use

- Studies frequentily collect GPS data
- Valuable time and location details

Controls needed to protect study partic
pant anonymity
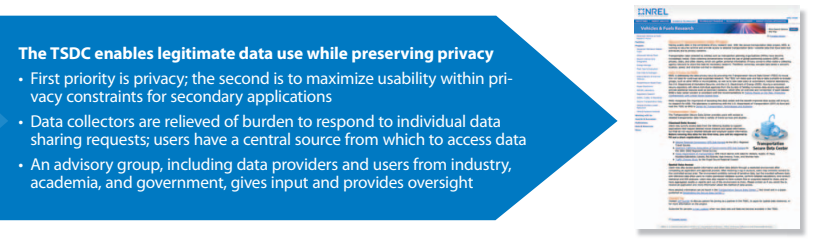

\section{EXAMPLE DATA AND USES}

REAL-WORLD FUEL ECONOMY

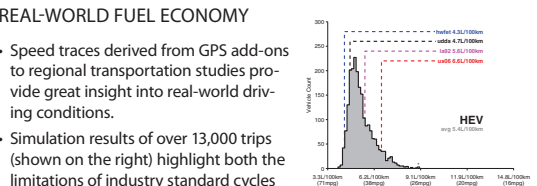

- Simulation results of over 13,000 trips

limitations of industry standard cycles and he sensitivity of powd
ciency to driving style.

\section{DRIVE DATA BY ROAD TYPE}

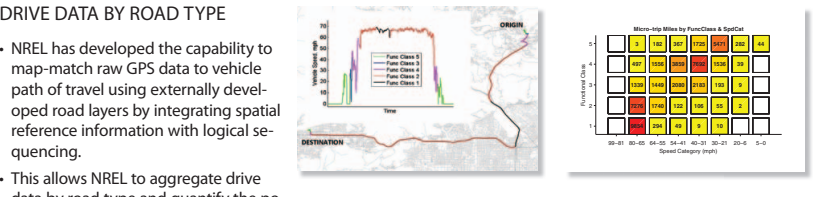

data by road type and quantify the po-

gies such as green routing route con-

nected controls, and wireless power

transfer to improve the efficiency of
commercial and personal transporta

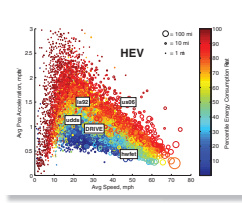

SPEED VISUALIZATION

Overlaid lines representing 470,000 trips in

Choices Study (PSRC TCS) prior to fitering.

- Spurious lines highlight erroneous GPS point

readings that are corrected during quality-

Trips are colored by spe

segments representing high-volume traffic

segments
corridors.

ONGITUDINAL TRAVEL PATTERNS

- The PSRC TCS collected 18 months of data

attle area to evaluate responses to time-

and location-variable road tolling.

The plot to the right shows an average
week of travel behavior for the study par-

ticipants.

- This dataset has been used extensively in
the economic analysis of advanced vehict

the economic analysis of advanced vehicle
technologies-such as plug-in hybrid elec-

tric and battery electric vehicles-to est-

mate consumer operating costs and the
fraction of miles achievable in charge-depleting mode.
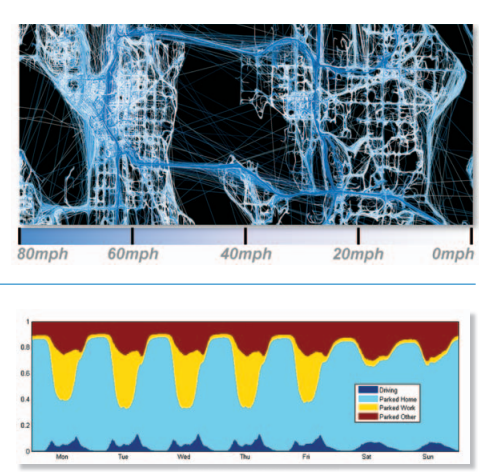

ACKNOWLEDGMENTS

This work is supported by the U.S. Department of Transportation,

Federal Highway Administration (U.S. DOT, FHWA) and the
U.S. Department of Energy Vehicle Technologies Program (US. DOE, VTT)
CONTACT INFORMATION

- To apply for spatial data access

-To discuss contributing

mail: jeff.gonder@enrel.gor

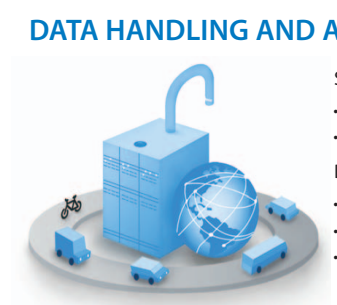

SECURE STORAGE

Co-located with another secure data center

Data archived and backed

DATA PROCESSING

- Standictize fomatting thousehold, vehicle, and point data

- Quality control

- Add reference information (road network, economic,
demographic, and land-use data)

DOWNLOADABLE CLEANSED DATA

- Public website with simple user registration - Trip summaries and second-by-second speed data
(with no latitude and longitude details)
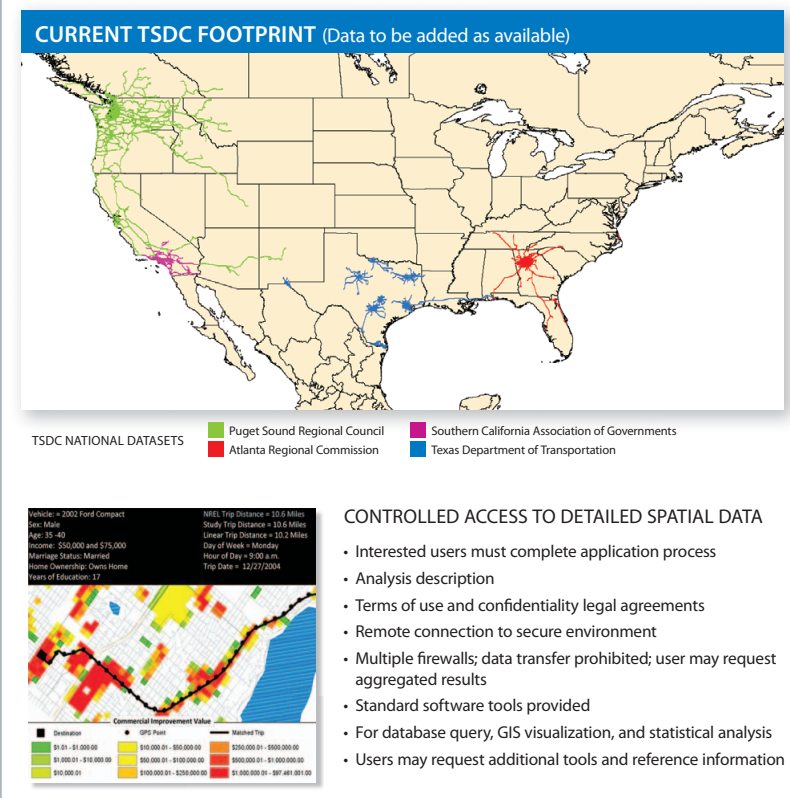

CONTROLLED ACCESS TO DETAILED SPATIAL DATA

- Interested users must complete application process - Analysis description

- Terms of use and confidentiality legal agreements - Remote connection to secure environment Standard softwar tool

tools provided

- For database query, GI visualization, and statistical analysis - Users may request additional tools and refersceinglonston 